\title{
Effects of zinc and aprotinin on the healing of ulnar diaphyseal fractures in rabbits
}

\author{
Celal İzci ${ }^{1}$ İlhami Çelik ${ }^{2}$, Muharrem Erol ${ }^{3}$ \\ ${ }^{1}$ University of Selçuk, Faculty of Veterinary Medicine, Department of Surgery, Konya, Turkey \\ ${ }^{2}$ University of Selçuk, Faculty of Veterinary Medicine, Department of Histology and Embryology, \\ Konya, Turkey \\ ${ }^{3}$ Balıkesir University, Faculty of Veterinary Medicine, Department of Surgery, Balıkesir, Turkey
}

Received June 14, 2016

Accepted May 15, 2018

\begin{abstract}
The effects of zinc and aprotinin on fracture healing in experimentally induced fractures were investigated by means of histometric analyses and alkaline phosphatase histochemistry. Healthy 54 adult New Zealand White female rabbits were separated into three groups as control, zinc, and aprotinin treatment. The control animals did not receive any medicament; zinc sulphate was given orally to the rabbits in the $\mathrm{Zn}$ group for 15 days. Aprotinin was postoperatively infiltrated into the fracture area at the $3^{\text {rd }}$ and $24^{\text {th }} \mathrm{h}$ following operation. Immobilization of fracture ends of all groups was similar throughout the experiment. The zinc administered group displayed the highest alkaline phosphatase positive cell level through the experiment. By day 30 after the operation, fibrocartilage and osseous tissues reached the highest levels in the zinc treated group. Based on the observation of augmented osseous tissue formation and increased alkaline phosphatase positive osteoblastic cell activity in the callus, it was conluded that $\mathrm{Zn}$ sulphate is a potent stimulator of bone formation by increasing mineralization in the fractured bone segments.
\end{abstract}

Callus formation, osteoblastic activity, alkaline phosphatase

Fracture healing is a complex process including new bone production and is closely related to bone metabolism. The metalloenzyme known as alkaline phosphatase (ALP) increases the local concentrations of inorganic phosphates by catalysing the hydrolysis of phosphomonoesters (Golub and Boesze-Battaglia 2007). Alkaline phosphatase is an ectoenzyme, which is either attached to the exterior face of the plasma membrane or released in the matrix vesicles rising by budding from the plasma membrane of osteoblasts, chondrocytes, odontoblasts, and cementoblasts. The high expression of ALP in calcifying tissues and the low expression or even absence in hypophosphatasia evidence the substantial functions of ALP in biomineralization. Phosphatidylserin-rich membranes attract annexins and permit them to form calcium channels, facilitating the entry of $\mathrm{Ca}^{+2}$ into matrix vesicles for crystal formation (Kirsch et al. 2000).

Zinc is an essential metal in humans and plays catalytic, structural, and regulatory roles in the biological system; it is therefore required in all living organisms for normal growth and development (Rucker et al. 2008). Since zinc effectively stimulates bone growth and mineralization (Merialdi et al. 2004), the metal is abundant in bone tissue and is needed to maintain bone mineral density and bone metabolism (Diamonde and Hurley 1970). The organic matrix proteins of the bone require adequate amounts of zinc for optimal function. Zinc acts as a cofactor for osteoblastic activity during bone formation and is required for maintaining peak bone mineral density and reducing the risk of fracture. Zinc may act as a local regulator of bone cell formation by stimulating the osteoblastic cell proliferation and differentiation, and also inhibiting osteoclast differentiation (Molokwu and $\mathrm{Li}$ 2006). Moreover, zinc functions as a metal component of ALP that plays a key role in the formation of new bone. Alkaline phosphatase contains 4 zinc atoms per molecule, 2

Address for correspondence:

Prof.Dr. Celal İzci

Department of Surgery

Faculty of Veterinary Medicine

University of Selcuk

Phone: +903322233579

42031, Kampüs, Konya, TURKEY 
of which are essential for the enzyme's activity (Parisi and Vallee 1969). As ALP-bound zinc is essential for the enzymatic activity of ALP (Molokwu and Li 2006), the activity of the enzyme decreases with zinc deficiency (Underwood 1977). Therefore, ALP is reported to be a potent stimulator of bone formation (Yamaguchi et al. 2000). Osteoblast and chondrocyte numbers are reduced in Zn deficiencies (Diamonde and Hurley 1970). Moonga and Dempster (1995) reported that $\mathrm{Zn}$ increases the osteoblastic cell activity; in contrast, it decreases osteoclastic activity. Increased ALP activity and collagenesis were found in the rat femur with a Zn supplemented diet (Yamaguchi and Takahashi 1987). Wey et al. (2014) theorized that zinc chloride $\left(\mathrm{ZnCl}_{2}\right)$ can be used as a novel orthobiologic bone-healing adjunct.

Aprotinin, as a proteinase inhibitor, inhibits fibrinolysis and protein catabolism as a polyvalent enzyme inhibitor complex, leading to the activation and acceleration of tissue repair (Akın 1980). Moreover, bone formation during fracture repair inevitably initiates within or around extra vascular deposits of a fibrin-rich matrix. In addition to a central role in haemostasis, fibrin also enhances bone repair by supporting migration of inflammatory and mesenchymal progenitor cells into the zone of injury. However, failure in removing fibrin from the fracture site severely impairs fracture vascularisation, precludes bone union, and results in robust heterotopic ossification (Yuasa et al. 2015).

The aim of this study was to investigate the osteoblastic activity in both $\mathrm{Zn}$ and aprotinin treated groups by means of identifying ALP-positive osteoblastic cell activity, tissue types, and morphometry of callus.

\section{Materials and Methods}

Animals and groups

This experimental project was approved by the Animal Use Committee of the University of Selcuk and all the animals were treated in accordance with the national or local animal welfare legislation which is based on the European Council Directive. A total of 54 healthy female adult New Zealand White rabbits were used in this study. All the rabbits were fed with standard feed and had free access to water throughout the experiment. The rabbits were divided into 3 groups of equal numbers as control, $\mathrm{Zn}$ and aprotinin treatment groups. The acclimation period prior to surgery was one week for all the rabbits.

\section{Surgical procedure}

A transverse osteotomy was done on the left ulna on the level of spatium interosseum antebrachium, under halothane (Halothan, Aventis Pharma, İstanbul, Turkey) anaesthesia using aseptic technique and taking adequate precautions the whole time in all rabbits. The operated legs were bandaged for the first week for protection from wound contamination in all groups. All rabbits were administered $3 \mathrm{mg} / \mathrm{kg}$ ketoprofen (Arveles amp., I.E. UlagayMenarini Pharma, İstanbul, Turkey) intramuscularly every $12 \mathrm{~h}$ after surgery for $24 \mathrm{~h}$ and as needed thereafter to control pain and discomfort, and the antibiotic $(30 \mathrm{mg} / \mathrm{kg}$ trimethoprim-sulphamethoxazole, Bactrim syrup, Roche, İstanbul, Turkey) orally post operation.

The animals in the control group did not receive any medication effective on bone metabolism. Rabbits in the $\mathrm{Zn}$ group received $100 \mathrm{mg} / \mathrm{kg}$ of $\mathrm{Zn}$ sulphate orally for 15 days. To make sure that the rabbits received the correct amount, Zn sulphate capsules (Zinco 220, Berko, Turkey) were dissolved in drinking water and administered by a nasogastric tube. In the aprotinin group, $25.000 \mathrm{IU}$ of aprotinin (Trasylol, Bayer, İstanbul,Turkey) were injected postoperatively under sterile conditions (Bakhshi et al. 2013) into the fracture zone of the animals, two times only, at 3 and $24 \mathrm{~h}$ following operation.

\section{Histology}

Six rabbits from each group were euthanized by overdose of pentobarbital (Pentothal Sodium, Abbott Corporation, Turkey) at 15, 21 and 30 days of the postoperative period. The ulna was totally removed and the soft tissues were dissected. From the bone samples of day 15, a segmental unit of callus $(2 \times 2 \mathrm{~mm}$ callus area) was harvested and fixed at $+4{ }^{\circ} \mathrm{C}$ in formal calcium for $24 \mathrm{~h}$, and then kept in Holt's solution for additional $24 \mathrm{~h}$. From the tissue samples, $12 \mu \mathrm{m}$ thick frozen sections were taken using the cryostat (Slee Corporation, London/ UK). Enzyme histochemical reaction was ascertained on the sections by a modified simultaneous azo-coupling method (Yoshiki et al. 1972). The sections were counterstained with methyl green nuclear stain and mounted with Kaiser's glycerol jelly.

The remaining tissue samples of day 15 and the samples of days 21 and 30 were fixed in the periodate-lysineparaformaldehyde (PLP) fixative (McLean and Nakane 1974), decalcified in an EDTA-G solution (Mori et al. 1988) and embedded in paraffin for histochemical demonstration of ALP (Yoshiki et al. 1972), and trichrome 
stain (Bancroft 1992). All specimens were examined under the Nikon Eclipse E-400 light microscope (Nikon Corporation, Japan). Total areas of connective tissue, fibrocartilage tissue, osseous tissue, porous regions, and blood vessels on each frame were determined on digital images by using an image analysis program (BS200 PRO, BAB Soft, Turkey). From the data, relative value for each indicator was calculated and expressed as percentage of the total image area. The number of ALP positive osteoblastic cells on $1.3 \times 10^{6} \mu \mathrm{m}^{2}$ tissue area was determined on each callus area of the rabbits.

\section{Statistics}

Statistical analyses were performed using the Standard Computer Program (SPSS version 15.0, SPSS, Chicago, IL, USA). The ALP positive osteoblastic cell scores of the groups were statistically analyzed with ANOVA. Wilcoxon test was used to evaluate the scores of connective tissue, fibrocartilage tissue, osseous tissue, porous regions and blood vessels in the callus of the groups. The significance of the differences between the mean scores of the groups was determined. Values at $P<0.05$ were considered significant.

\section{Results}

No systemic disturbances attributable to the operation and used medicaments were observed in the animals throughout the experiment. Macroscopic evaluation of the callus revealed no difference between the three groups.

In the ALP demonstrated specimens, the presence of pinkish-red coloured reaction product in the cytoplasm and at the cell border was regarded as positive for ALP (Plate IV, Figs 1-2, Plate V, Fig 3). The ALP positive cell levels (cell number/1.3 $\times 10^{6} \mu \mathrm{m}^{2}$ tissue area) gradually increased in the callus area of all groups. The zinc administered group had significantly higher $(P<0.05)$ levels of ALP positive cells throughout the experiment, followed by the aprotinin group (Fig. 4).

At 15 days of the postoperative period, the connective tissue level was higher in both the control and aprotinin group compared to the zinc treated group (Fig 5) (Plate V, Fig 6, Plate VI, Figs 7-8). The highest fibrocartilage, osseous tissue, and vascular area rates were found

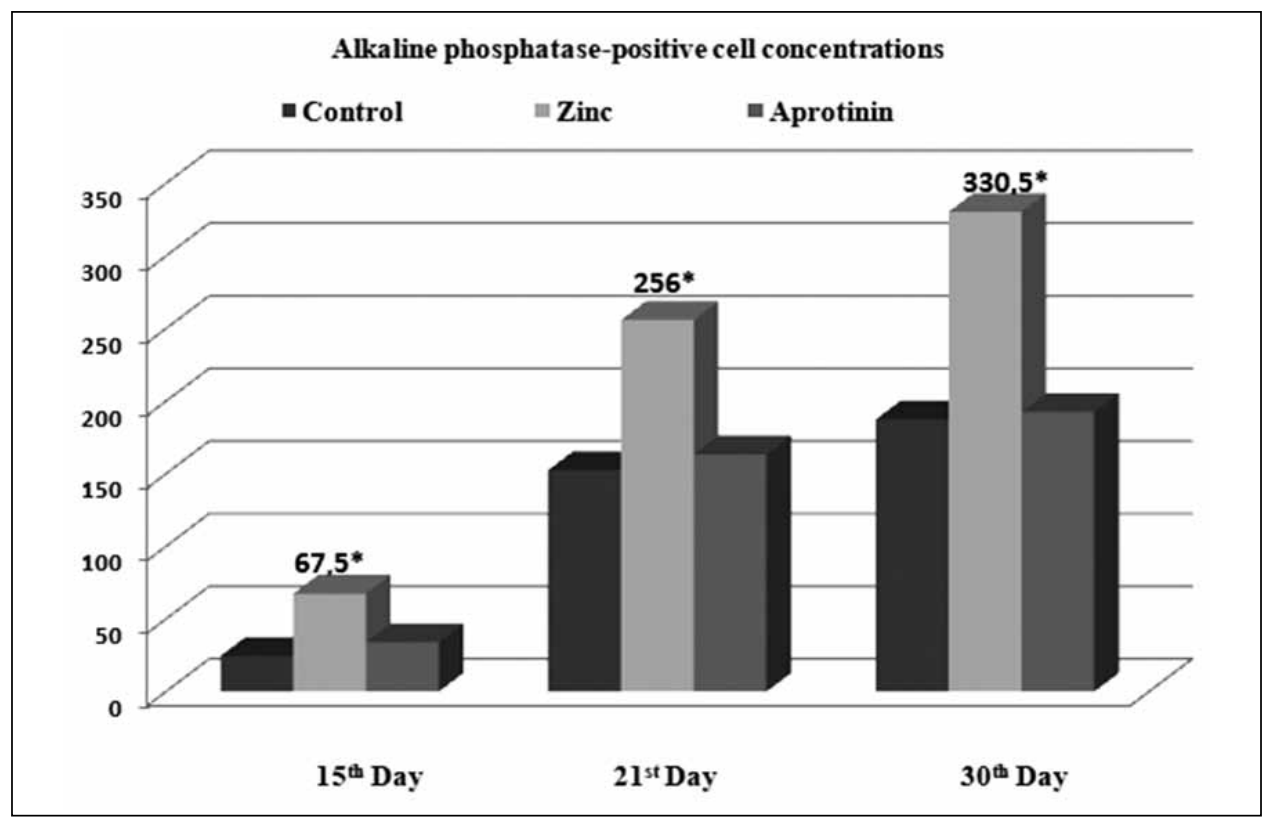

Fig. 4. Alkaline phosphatase positive cell concentrations of the groups in different periods of the experiment in the callus area. 


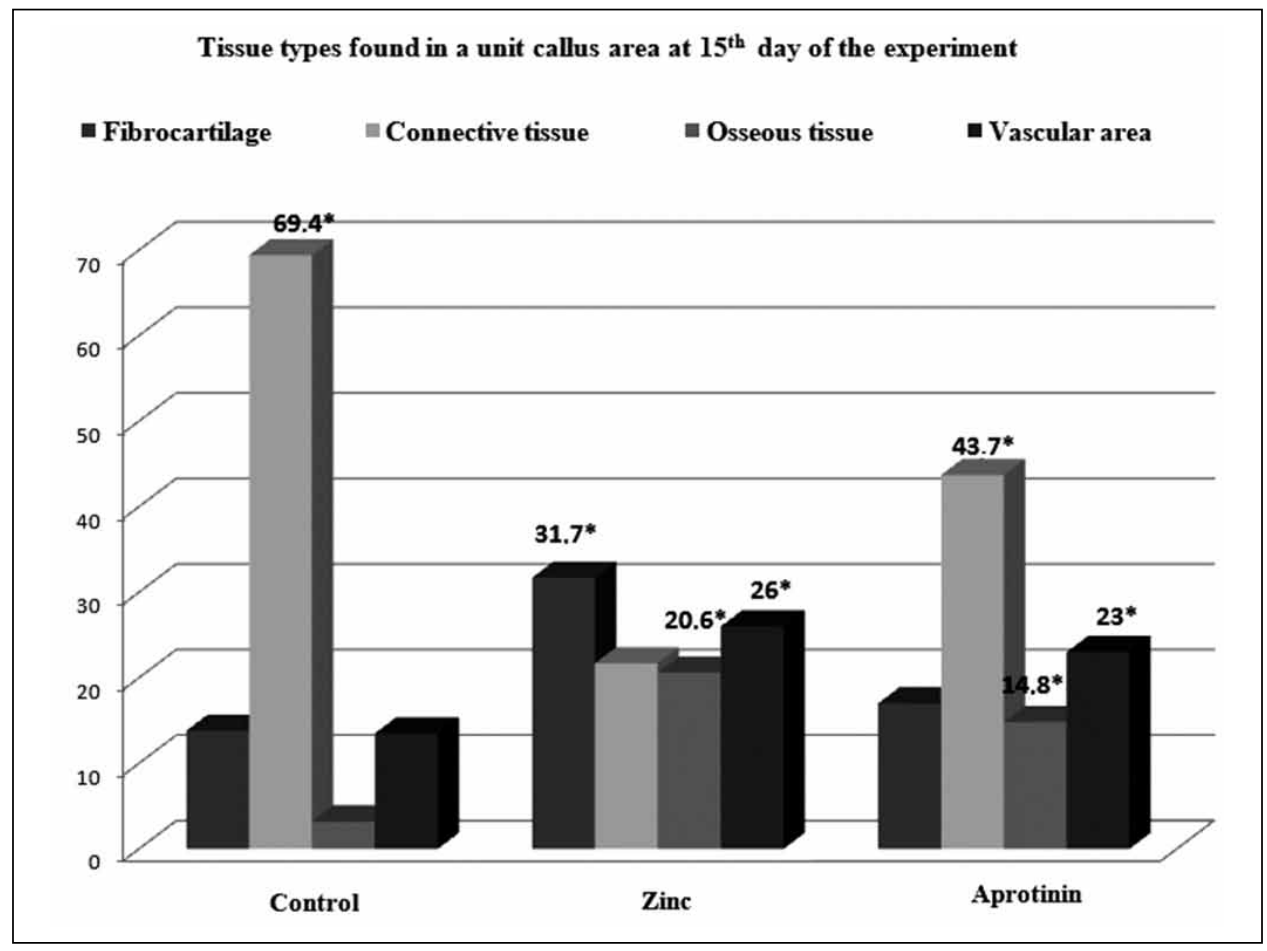

Fig. 5. Percentages of the tissue types found in a unit callus area of the groups on day 15 of the experiment.

in the zinc treated group $(P<0.05)$. However, the osseous tissue and vascular area ratios of the zinc and aprotinin treated groups were quite similar $(P>0.05)$.

By day 21 after the operation, the highest connective tissue ratio $(P<0.05)$ was found in the control group. Fibrocartilage and osseous tissues reached the highest levels in the zinc treated group. The control and aprotinin administered groups had similar rates of fibrocartilage and osseous tissues $(P>0.05)$. The vascular area of the groups had similar levels $(P>0.05)$ at this period of the experiment (Fig. 9).

On the postoperative day 30 , connective tissue and vascular area rates of the control group were higher than the zinc and aprotinin administered groups (Fig. 10). The zinc treated group had the highest fibrocartilage and osseous tissues $(P<0.05)$.

\section{Discussion}

In our study, the fractured regions in all groups displayed similar macroscopic findings. Repair of bone fracture takes place with the formation of newly developing osseous tissue via complex histological and biochemical mechanisms. During fracture healing, three main steps take place, namely, the production of the extracellular organic matrix, the mineralization of the matrix to form bone, and bone remodelling by resorption and deposition (Molokwu and Li 2006). The cellular activities of osteoblasts, osteocytes and osteoclasts are necessary for this process. Zinc plays a crucial role in every step of bone metabolism. It is known to play a key role in regulating cellular activity by acting as a cofactor and stimulating protein synthesis needed for collagen formation. Collagen 


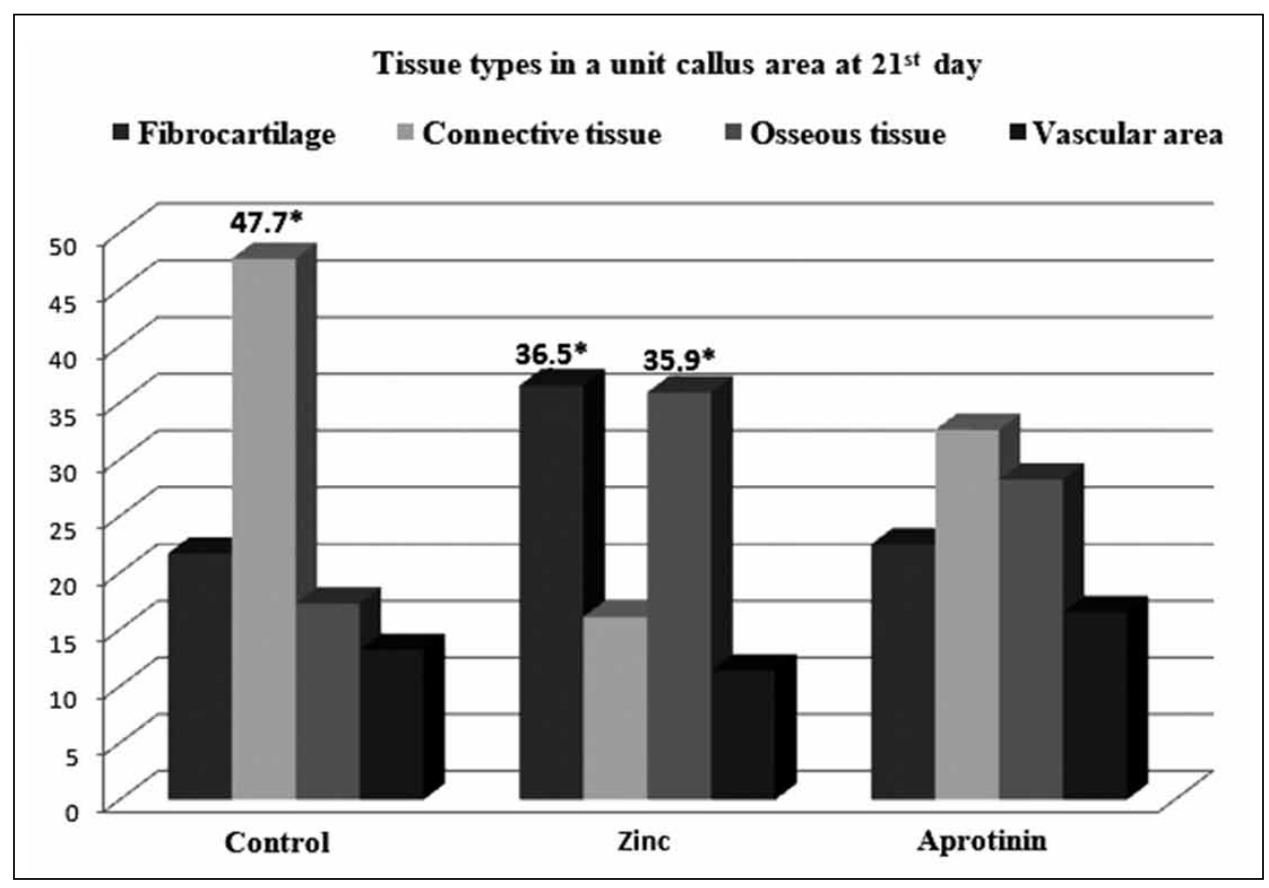

Fig. 9. Percentages of the tissue types found in a unit callus area of the groups on day 21 of the experiment.

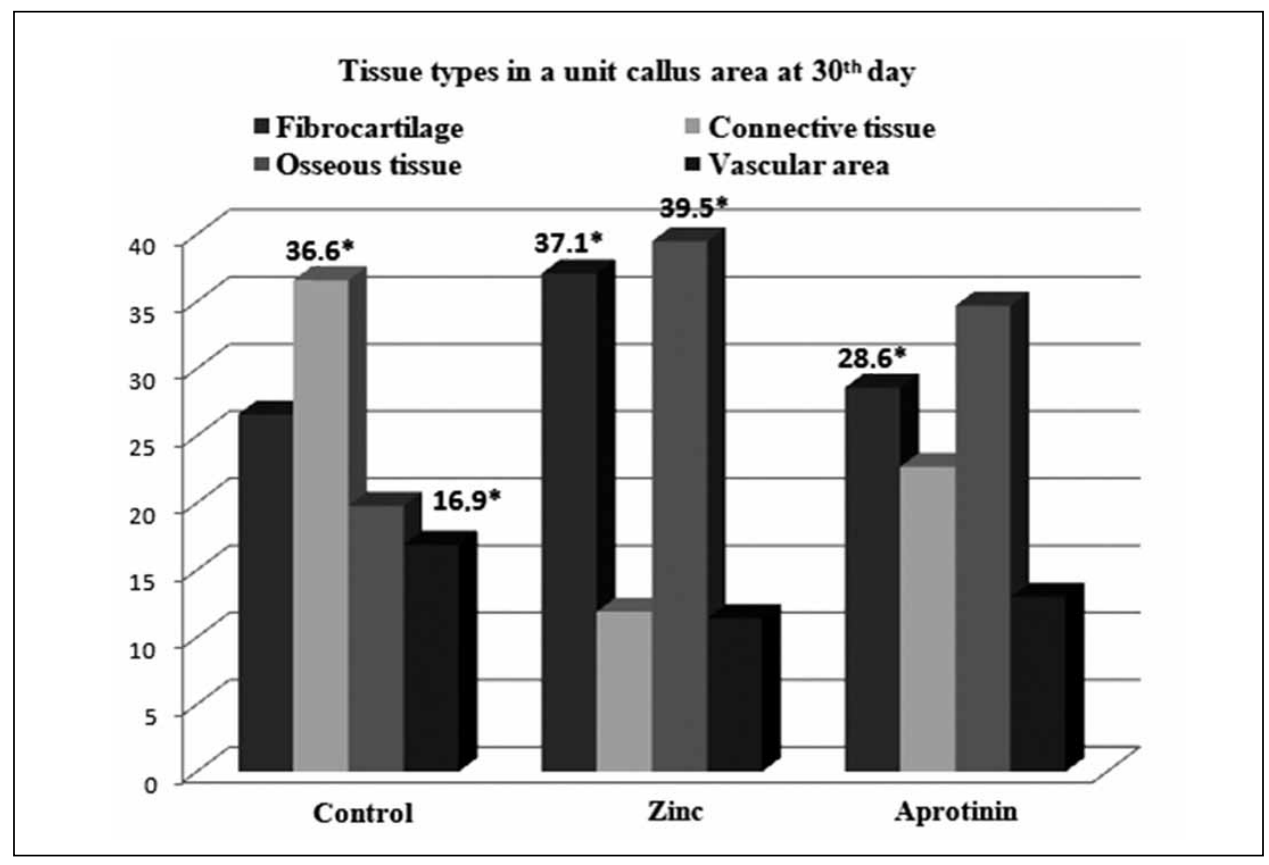

Fig. 10. Percentages of the tissue types found in a unit callus area of the groups on day 30 of the experiment. 
comprises $90 \%$ to $95 \%$ of the organic matrix of bone and forms the structural framework around which mineralization occurs (Lowe et al. 2002).

Some factors as markers of bone metabolism have a role in the formation or destruction of bone. One of the most important of these factors is ALP and the number of ALP synthesizing cells in the callus (Price et al. 1980; Bowles et al.1996; Kent 1997). Alkaline phosphatase is necessary for bone production and mineralization (Fallon et al. 1980; Yoon et al. 1989) and produced mainly during the fracture healing by osteoblasts (Moss 1992). In the current study, ALP positive cells were seen in the callus in all groups, and their level was higher in the zinc treated group throughout the experiment compared to the other groups. Alkaline phosphatase is a Zn-containing metalloenzyme, which is present on the osteoblast surface and activated by Zn (Moss 1992; Dimai et al. 1998).

Recent investigations have shed new light on the mechanism of ALP action on mineralization. As more has been learned about the biology of hard tissues and mineral metabolism, the role of ALP as a marker of osteogenic activity has been consistently solidified (Golub and Boesze-Battaglia 2007). Bone ALP enzyme has been regarded as one of the most important markers of bone formation (Price et al. 1980; Fallon et al. 1980; Yoon et al. 1989; Bowles et al. 1996; Kent 1997). Thus, the increase in ALP expression is assumed to be a reliable indication of increased activities of the osteoblastic, chondrocytic or odontoblastic cells (Golub and Boesze-Battaglia 2007). Alkaline phosphatase has become the marker of choice when assessing the phenotype or developmental maturity of mineralized tissue cells. Golub and Boesze-Battaglia (2007) have suggested that ALP expression declines at later phases of fracture healing, thus ALP must function in the initial phases of the mineralization process. Nevertheless, in our study, ALP positive cell levels tended to increase regularly at later stages of fracture healing. Although this inconsistency needs to be clarified, the difference might have arisen from the increase of both the fibrocartilage tissue rate in the callus and the relative number of ALP positive cells in the fibrocartilage.

In a previous experiment, Volpin et al. (1986) reported that calcification of the fibrocartilaginous callus takes place within and around extracellular matrix vesicles which are formed by budding from the cytoplasmic processes of early hypertrophic cartilage cells. The researchers (Volpin et al. 1986) observed ALP activity around the plasma membrane of chondrocytes, during successive stages of differentiation and development of the cartilaginous callus. In the present study, ALP activity was observed both in the cytoplasm of osteoblastic cells and at the cell borders at light microscopic level. This finding might show the functional association between ALP activity and calcification mediated by extracellular matrix vesicles during the process of experimental fracture healing.

Zinc is an essential, relatively nontoxic trace element and component of many enzymes, effective in a variety of metabolic functions. Toxicity occurs when received at $\times 50$ higher dose than the recommended daily dose (Rucker et al. 2008). In our study, medication of rabbits with $100 \mathrm{mg} / \mathrm{kg} \mathrm{Zn}$ sulphate orally by a stomach tube showed no toxic effect throughout the experiment. Previously, researchers have reported that $\mathrm{Zn}$ increases the ALP activity during fracture healing (Igarashi and Yamaguchi 1999a; Igarashi and Yamaguchi 1999b). Alkaline phosphatase positive osteoblastic cell level of the zinc treated group tended to be significantly $(P<0.05)$ higher compared to those of the control and aprotinin administered groups. This finding might be the evidence of the relation between $\mathrm{Zn}$ and the role of ALP in mineralization of the callus. Molecular studies have revealed that $\mathrm{Zn}$ induces an increase in ALP-related DNA synthesis resulting in stimulation of bone growth (Hassan et al. 2007). In addition to its direct stimulatory effect on ALP and osteocalcin (Ketteler and Giachelli 2006), Zn promotes bone mineralization as a cofactor in alkaline phosphatase (Towler et al. 2006). Zinc also regulates the activity of cells involved in the formation of the bony framework by increasing the 
synthesis of growth factors such as insulin like growth factor-1 (IGF-1) and the effect on target tissues.

Previously, researchers demonstrated the augmenting effect of $\mathrm{Zn}$ at high doses on the femoral diaphyseal fracture healing in rats with measurements of $\mathrm{Zn}$ and ALP levels in the fractured callus zone (Igarashi and Yamaguchi 1999a; Igarashi and Yamaguchi $1999 b$ ). The observation of high percentages of fibrocartilage in the $\mathrm{Zn}$ group compared to the control and aprotinin groups evidences the efficacy of $\mathrm{Zn}$ on fibroblast and chondrocyte activities, and is consistent with the findings of previous studies (Igarashi and Yamaguchi 1999a; Igarashi and Yamaguchi 1999b). In the current study, the significant $(P<0.05)$ increase of bone formation in favour of the $\mathrm{Zn}$ group compared to the control and aprotinin groups underlines the importance of $\mathrm{Zn}$ as a potent stimulator of bone production, which is in agreement with previous reports (Yamaguchi et al. 1987; Yamaguchi et al. 2000). Since $\mathrm{Zn}$ is required for osteoblastic activity, it has multiple important functions in the bone development, formation, and metabolism (Golub and Boesze-Battaglia 2007).

As an anti-fibrinolytic agent a proteinase inhibitor, aprotinin inhibits protein degradation and leads to the activation and acceleration of tissue repair (Ak1n 1980). It also plays an essential role at a relatively early period of healing. Thus, failure in removing fibrin from the fracture site severely impairs fracture vascularisation, precludes bone union, and results in robust heterotopic ossification (Yuasa et al. 2015). In the present study, osseous tissue and vascular area ratios of the zinc and aprotinin administered groups were similar and higher than that of the control group on day 15 of the experiment. By day 21 after operation, the control and aprotinin administered groups had similar rates of fibrocartilage and osseous tissues and vascular area. On the postoperative day 30, the zinc and aprotinin treated groups had similar fibrocartilage rates. Previous studies suggested that fibrin is not essential for fracture repair, and indeed, fibrin must be timely and effectively removed to allow fracture vascularisation and repair (Yuasa et al. 2015). Moreover, inefficient fibrinolysis decreases endochondral angiogenesis and ossification, thereby inhibiting fracture repair. Since impaired angiogenesis is hypothesized to be a primary cause of delayed union or non-union, persistent or excessive fibrin deposition at the fracture site might cause impaired fracture angiogenesis and subsequent delayed union or non-union in these conditions (Willigendael et al. 2004).

The results of the present experiment revealed that osseous tissue rates and ALP positive osteoblastic cell levels were significantly $(P<0.05)$ increased in the callus of $\mathrm{Zn}$ treated group. In conclusion, $\mathrm{Zn}$ is as a potent stimulator of bone formation by increasing mineralization via augmenting the ALP activity in the fractured bone segments. In the current study, $\mathrm{Zn}$ sulphate was experimentally administered by a nasogastric tube. Nevertheless, this administration route may not be practical in the clinical use. For this reason, further studies evaluating positive effects of different $\mathrm{Zn}$ compounds on fracture healing are necessary. Moreover, a practical administration route of the most active compound should be developed before use in clinical practise.

\section{Acknowledgements}

This work was supported by a grant from University of Selcuk, Konya, Turkey with project no: BAPVF-111/2003.

\section{References}

Akın F 1980: Contribution à l'étude des effects de Trasyloledans le traitement les blessures post-opératories. AÜ Vet Fak Derg 26: 263-291

Bancroft JD 1992: Connective tissues and stains. In: Bancoft JD, Stevens A (Eds): Theory and Practice of Histological Techniques. Churchill Livingstone Avon, pp 119-153

Bakhshi H, Kazemian G, Emami M, Nemati A, Yarandi HK, Safdari F 2013: Local erythropoietin injection in tibiofibular fracture healing. Trauma Mon 17: $386-388$ 
Bowles S, Kurdy N, Davis AM, France MW, Marsh DR 1996: Serum osteocalcin, total and bone specific alkaline phosphatase following isolated tibial shaft fracture. Ann Clin Biochem 33: 196-200

Diamonde I, Hurley LS 1970: Histopathology of zinc deficient rats. J Nutr 100: 325-329

Dimai HP, Hall SL, Stilt-Coffing B, Farley JR 1998: Skeletal response to dietary zinc in adult female mice. Calcif Tissue Int 62: 309-315

Fallon MD, Whyte MP, Teitelbaum SL 1980: Stereo specific inhibition of alkaline phosphatase by L-tetramisole prevents in vitro cartilage calcification. Lab Invest 43: 489-494

Golub EE, Boesze-Battaglia AK 2007: The role of alkaline phosphatase in mineralization. Curr Opin Orthop 18: 444-448

Hassan MQ, Tare R, Lee SH, Mandeville M, Weine RB, Montecino M, Van Wijnen A, Janet L, Stein JL, Stein GS, Jane B, Lian JB 2007: HOXA10 controls osteoblastogenesis by directly activating bone regulatory and phenotypic genes. Mol Cell Biol 27: 3337-3352

Igarashi A, Yamaguchi M 1999a: Increase in bone protein component with healing rat fractures, enhancement by zinc treatment. Int J Mol Med 4: 615-620

Igarashi A, Yamaguchi M 1999b: Stimulatory effect of zinc acexamate administration on fracture healing of the femoral diaphyseal tissue in rats. Gen Pharmacol 32: 463-469

Kent GN 1997: Markers of bone turnover. JIFFC9: 31-35

Ketteler M, Giachelli C 2006: Novel insights into vascular calcification. Kidney Int 69: (Suppl. 105): S5-S9

Kirsch T, Harrison G, Golub EE, Nah HD 2000: The roles of annexins and types II and X collagen in matrix vesicle-mediated mineralization of growth plate cartilage. J Biol Chem 275: 35577-35583

Lowe NM, Lowe NM, Fraser WD and Jackson MJ 2002: Is there a potential therapeutic value of copper and zinc for osteoporosis? Proc Nutr Soc 61: 181-185

Mc Lean I, Nakane P 1974: Periodate-lysine-paraformaldehyde fixative: a new fixative for immunoelectron microscopy. J Histochem Cytochem 22: 1077-1083

Merialdi M, Caulfield LE, Zavaleta N, Figueroa A, Costigan KA, Dominici F, Di Pietro JA 2004: Randomized controlled trial of prenatal zinc supplementation and fetal bone growth. Am J Clin Nutr 79: 826-830

Molokwu CO, Li YV 2006: Zinc homeostasis and bone mineral density. OhioRes Clin Rev 15: 1-15

Moonga BS, Dempster DW 1995. Zinc is a potent inhibitor of osteoclastic bone resorption in vitro. J Bone Miner Res 10: 453-457

Mori S, Sawai T, Teshima T, Kyogoku M 1988: A new decalcifying technique for immunohistochemical studies of calcified tissue, especially applicable to cell surface marker demonstration. J Histochem Cytochem 36:111-114

Moss DW 1992: Perspectives in alkaline phosphatase research. Clin Chem 38: 2486-2492

Parisi AF, Vallee BL 1969: Zinc metalloenzymes: characteristics and significance in biology and medicine. Am J Clin Nutr 22: 1222-1239

Price PA, Parthemore JG, Reftos U 1980: New biochemical marker for bone metabolism. J Clin Inves 66: 878-883

Rucker RB, Fascetti AJ, Keen CL 2008: Trace minerals. In: Kaneko LS (ed.) Clinical Biochemistry of Domestic Animals. Academic Press Inc, London, pp 663-693

Towler DA, Shao JS, Cheng SL, Pingsterhaus JM, Loewy AP 2006: Osteogenic regulation of vascular calcification. Ann NY Acad Sci 1068: 327-333

Underwood EJ 1977: Zinc. In: Underwood EJ (Aut.): Trace Elements in Human and Animal Nutrition. Academic Press, New York, pp 196-242

Volpin G, Rees JA, Ali SY, Bentley G 1986: Distribution of alkaline phosphatase activity in experimentally produced callus in rats. J Bone Joint Surg Br 4: 629-634

Wey A, Cunningham C, Hreha J, Breitbart E,Cottrell J, Ippolito J, Clark D, Lin Hn, Benevenia J, O’Connor JP, Lin SS, Paglia DN 2014: Local $\mathrm{ZnCl}_{2}$ accelerates fracture healing. J Orthop Res 32: 834-841

Willigendael EM, Teijink JA, Bartelink ML, Kuiken BW, Boiten J, Moll FL, Büller HR, Prins MH 2004: Influence of smoking on incidence and prevalence of peripheral arterial disease. J Vasc Surg 6: 1158-1165

Yamaguchi M, Takahashi K 1987: Role of zinc as an activator of bone metabolism in weanling rats. Jpn J Bone Miner Res 2: 186-191

Yamaguchi M, Oishi H, Suketa Y 1987: Stimulatory effect of zinc on bone formation in tissue culture. Biochem Pharmacol 36: 4007-4012

Yamaguchi M, Gao YH, MA ZJ 2000: Synergistic effect of genistein and zinc on bone components in the femoral metaphyseal tissues of female rats. J Bone Miner Metab 18: 77-83

Yoon K, Golub E, Rodan GA 1989: Alkaline phosphatase cDNA transfected cells promote calcium and phosphorus deposition. Connect Tiss Res 22: 17-25

Yoshiki S, Umeda T, Kurahashi Y 1972: An effect reactivation of alkaline phosphatase in hard tissues completely decalcified for light and electron microscopy. Histochemie 29: 296-304

Yuasa M, Mignemi NA, Nyman JS, Duvall CL, Schwartz HS, Okawa A, Yoshii T, Bhattacharjee G, Zhao C, Bible JE, Obremskey WT, Flick MJ, Degen JL, Barnett JV, Cates JMM, Schoenecker JG 2015: Fibrinolysis is essential for fracture repair and prevention of heterotopic ossification. J Clin Invest 8: 3117-3131 
Plate IV

Izci C. et al.: Effects of zinc ... pp. 137-144

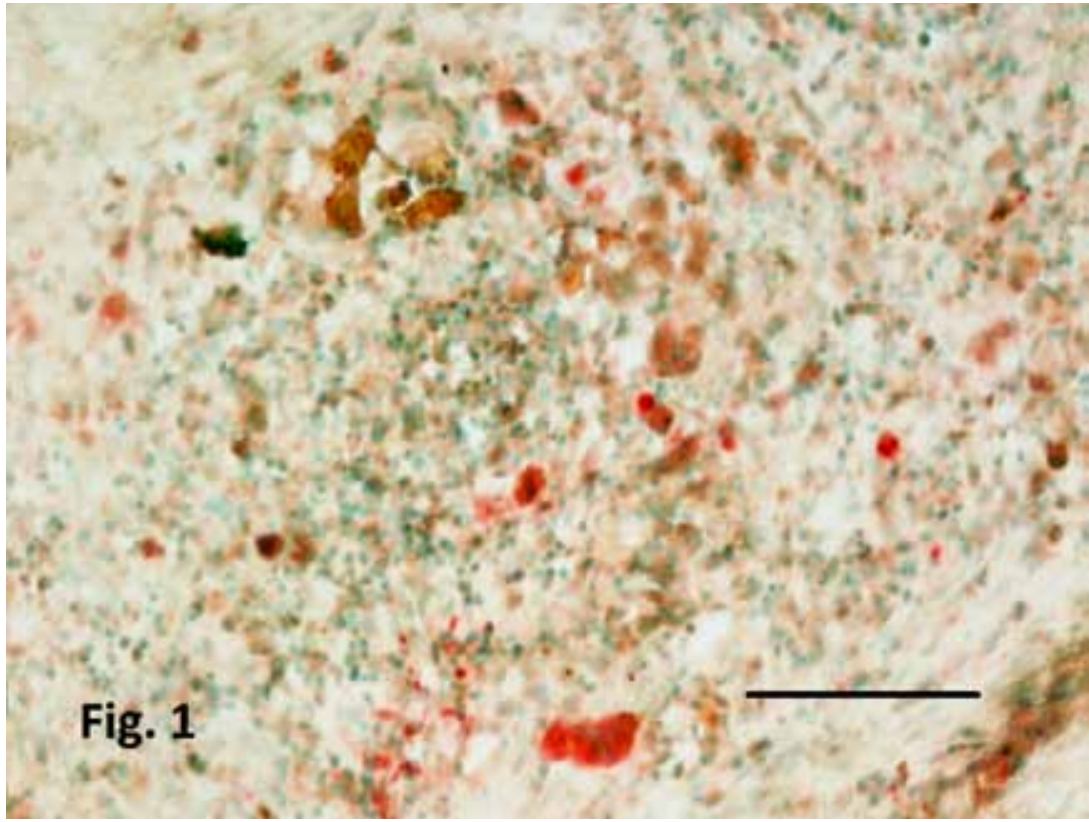

Fig. 1. Alkaline phosphatase positive individual osteoblastic cells in the fibrous connective tissue of the control group on day 15 . Reddish cytoplasmic reaction is definite. Alkaline phosphatase demonstration, magnification bar: $500 \mu \mathrm{m}$.

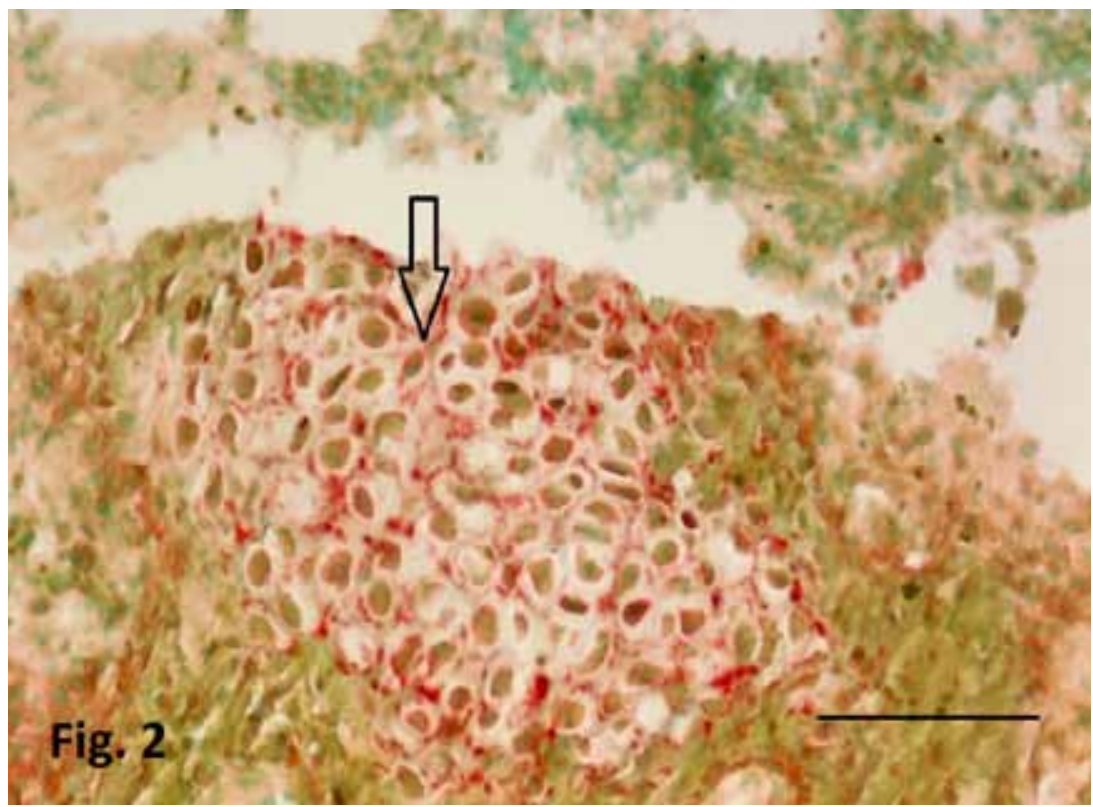

Fig. 2. Alkaline phosphatase positive osteoblastic cells in fibrocartilage (arrow) of the aprotinin administered group on day 15. Enzymatic positivity is peculiar to the osteoblastic cell borders. Alkaline phosphatase demonstration, magnification bar: $500 \mu \mathrm{m}$. 


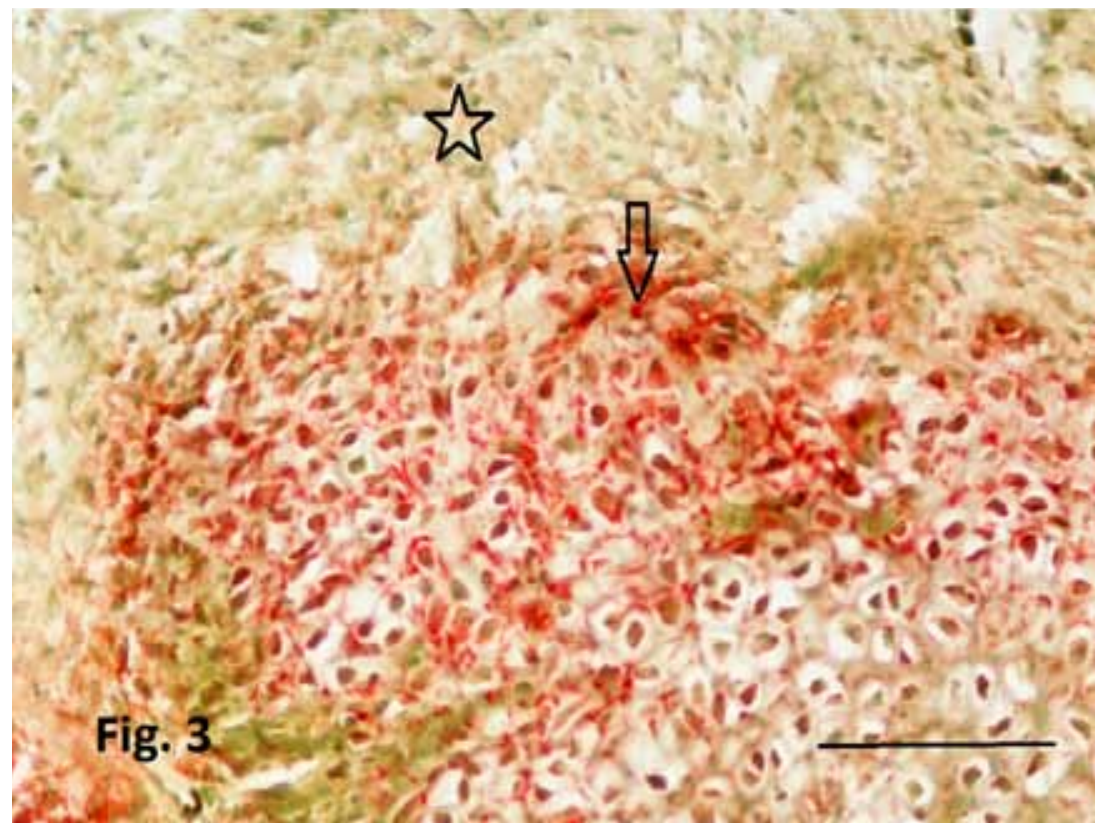

Fig. 3. Alkaline phosphatase positive osteoblastic cells (arrow) in fibrocartilage tissue surrounded by connective tissue (asterisk) of the zinc treated group on day 15. Enzymatic positivity is definite at the cell borders. Alkaline phosphatase demonstration, magnification bar: $500 \mu \mathrm{m}$.

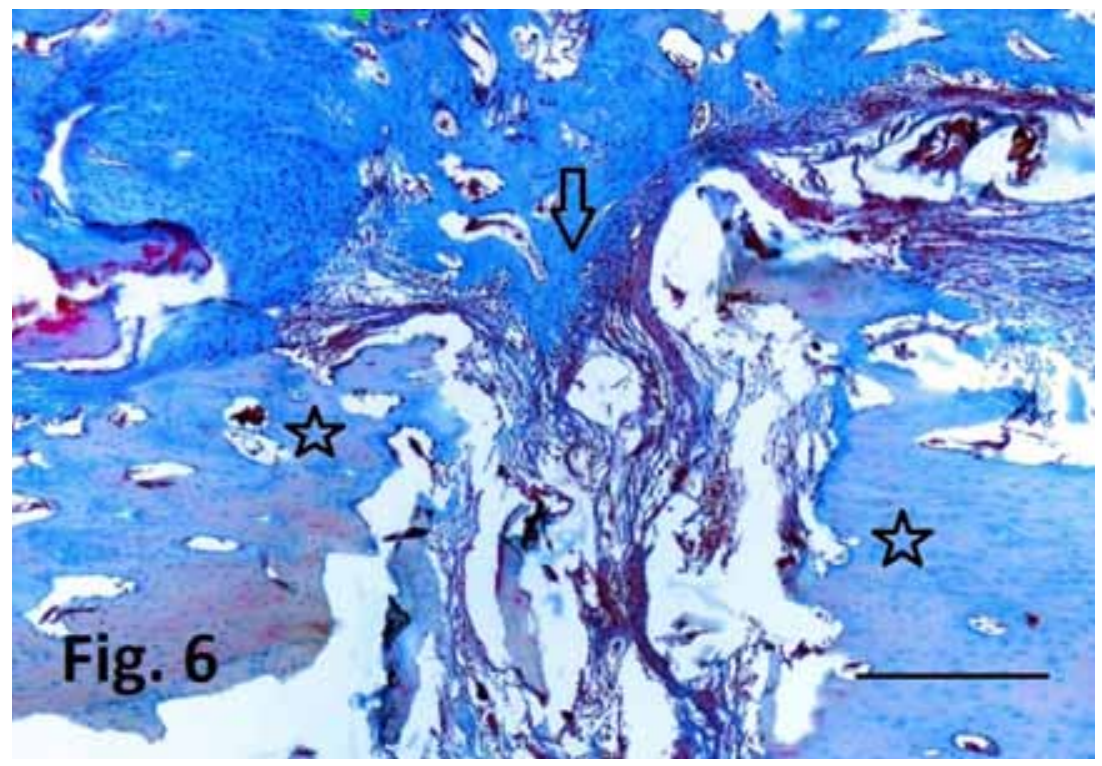

Fig. 6. Fracture line of the control group after 15 days from the surgery. The fracture line is mostly filled with fibrous connective tissue, fibrocartilage tissue (arrow) and blood vessels. Attachment of the fracture ends to the cortical bone (asterisks) is relatively weak. Pappenheim's panoptic stain, magnification bar: $500 \mu \mathrm{m}$. 


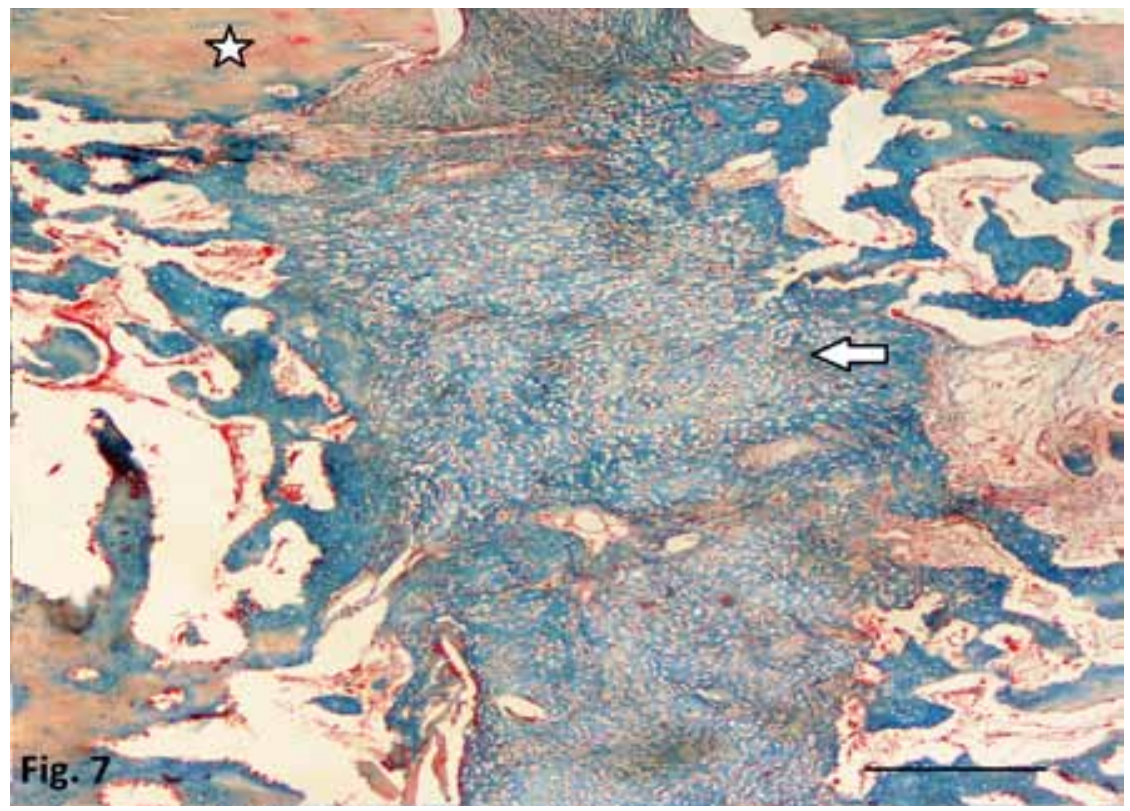

Fig. 7. Fracture line of the zinc treated group after 15 days from the surgery. The fracture line is filled mostly with fibrocartilage (arrow), newly formed bone tissue and blood vessels. Attachment of the callus to the cortical bone (asterisk) is stronger.

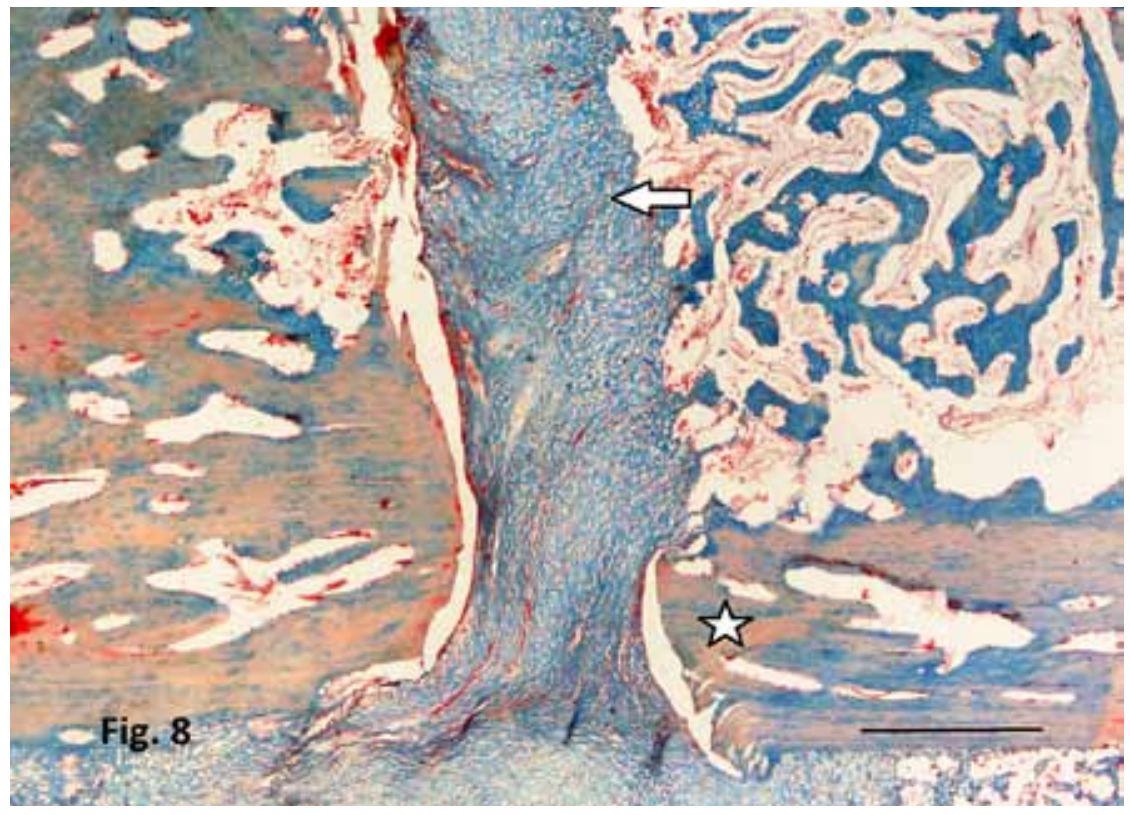

Fig. 8. Fracture line of the approtinin administered group on day 15 after the surgery. The fracture line is occupied mostly by fibrocartilage (arrow), newly formed bone tissue and vessels. Attachment of callus (arrow) to the cortical bone (asterisk) is relatively weaker than that of the zinc treated group. Trichrome stain, magnification bar: $500 \mu \mathrm{m}$. 